\title{
Conscious and Unconscious Aspects of Teacher-Student Interactions within a High School for Young Adults
}

\author{
Ruzhena Voynova, Jean-Marie Weber \\ University of Luxembourg
}

\begin{abstract}
Our hypermodern society, focused on knowledge constantly brings new recommendations; the pedagogical field is at the centre of the geopolitical and ideological struggles. These create ambiguities, cleavages and paradoxes that call into question the meaning and existence of the school institution [1]. New frameworks arise within the academic system to face an increasingly heterogeneous school, increases in pupil failure and dropout, and so on. With this paper, we will present the outcomes of a three-years research project on school dropouts. We will focus on the impact of the institutional context, namely on how teachers build their professional identity from their interactions with pupils and how those interactions interfere with students' commitment to academic success. We conducted three narrative interviews per participant with teachers from a high school for young adults, and students from the same school. Teachers' commitment to students' academic success is strong, due in part to the particular institutional set-ups such as tutoring and a consistently small number of students in each classroom. This institutional framework favours the relationship between teacher and pupil, which, once established, has a significant impact on how student approach the school, as well as on how they develop their relation to knowledge in particular. Thereby, students are more likely to pursue their schooling because they feel comfortable with and supported by their teachers, as we will discover in their interviews. Beside the positive outcomes from such a framework, we found out that teachers show signs of suffering at the hands of these set-ups, as they don't feel prepared for such an 'intense' involvement in both students' personal and scholarly lives. The pedagogical act of a teacher is conditioned by one's subjectivity, the unconscious desire to transmit knowledge, but also by the impact of institutional discourses. The need for teacher of training and supervision is evident and highly recommended.
\end{abstract}

\section{Introduction}

School drop-out is one of the priorities of researchers whose recent, and not so recent, studies show multifactorial causality. Its complexity stems from the varied processes of social and family ties, yet also has political roots when economic inequalities de facto aggravate inequalities in school learning. Among current research, our study addresses this issue of 'dropping out of school' as a response to a singular process, fitting in individual biographies constructed by the interactions and bonds among family, school and society.

For some students, school could be nothing but a constraint, with its rules, its authority, its demands, and no longer fulfils a function of container but rather of expelling. For some young people, the school may prove to be a staging ground for a personal life that is otherwise a source of suffering by lack of subjective recognition. Teachers, on the other side, are driven by the school system requirements: official scholarly program to be respected; obtaining the expected results and so on. They are under pressure to fulfil their mission, which is particularly true within classic academic world, where the institution shows less support due, on one hand, to the many requests they must deal with.

Subject to the hypermodern societal discourse of the primacy of science and technology [2], schools are experiencing an increase in established standards and in requirements for standardization. Although, "you can explain something but it is not seen directly in the compositions for example. And it's (teaching) not like an artisan who has an immediate result. ". Assessed by international evaluation devices, the school is then asked to produce performance [3]. An undeviating consequence for teachers is explained as follows by themselves: "If you have a lot of insufficient notes you are asking yourself questions, you think 'I did not explain the problem well'. And in general, it destroys the atmosphere in a class; that also, it is a failure ".

The students spend most of their time at school, interacting with each other, learning one way or another, admiring and/or disliking teachers. Students often feel that they are not being asked to think and acquire knowledge of the world, society, others, or themselves; rather, they see school as a matter of accumulating knowledge in order to reproduce it during final exams. They seem to not understand the meaning of being at school, yet most of them are able to realize that they need the ending certificate in order to have a better and richer life afterwards. "For me the finals are something that have nothing to do with the intellect, it is a paper that society requires so that we can continue to have a good life, but for 
the rest it is worth not big thing.". Hereby, it is a question of learning a great deal of things without any deep understanding of them, beyond, for example, simple mathematics formulas.

Many students realize that even knowledge is a commercial object. Indeed, in our modern technology era, everyone may access virtually any known information when they need it. Most young people, whose desire for knowledge and relation to school seem to therefore be severely disrupted, find it impossible to continue their schooling, thus inscribing their singularity in the collective. Some of them, influenced by the discourses and desires of their relatives, and the school as an institution, are prisoners of an almost morbid monotony. The question of desire seems to no longer arise for them.

However, school, must be the place where one learns how to reflect on knowledge and think critically, as well as how to understand the why-ofhow, causes-to-effects, dynamic processes, and other important lessons beyond how to memorize a pile of information. Freud [4] speaks of the school as a place where one must play life; in other words, school should open pupils to realize that they are not alone in asking themselves existential questions about life, death and self [5]. Thereby, the school must be this place where knowledge is articulated and conveyed by a body of teachers, bonded by a personal link rather than the anonymous one of the Web [5]. "If, with a student at the beginning, the relationship does not go through, it is my duty to try to make the relationship pass, especially if we block each other either on a personal level or on the level of the matter. It will not work ". The involvement of teachers beyond their specific field plays a great role in students' desire to learn.

Furthermore, the subjectivity only exists in the field of speech and language [6], under condition that we consider the notion of "word" in its double verbal and non-verbal acceptation (such as smiles, mimicry, gestures of tenderness or anger, of progress or retreat, looks, attention or ignorance). The body reveals, by its nonverbal language, support or refusal, presence or abandonment, trust or fear. In order to understand how school can be understood as an institution contributing to students' selfconstruction, we need to look at how it organizes and shapes bodies and words, how these are perceived, and the effects they may produce on the psyches. In this perspective, the dimension of knowledge, the organizing axis of the school, cannot be forgotten. It is in fact, through what they know, or must know, that individuals are defined in the school setting [7].

This said, with this paper, we will present one side of our study's results, which shows the importance of a respectful, meaningful and qualitative relationship between teachers and their students. This connexion helps to motivate, stimulate and keep in school those students who have previously dropped out and have decided to return to obtain their certificate. We chose to incorporate interview quotes in the main text that illustrate our thoughts and theories, as many teachers and students are mostly concerned by this topic. It is essential, in our opinion, to stay centred on what they think and how they deal with school and daily issues; this is one original element of our study. This aspect of our research came up to us while we were working on our theoretical research. The importance of teacherstudent relations is a widely studied topic in the educational research field in general [8]; [9]; [10]. However, we were surprised to not find more literature about the school environment and teacherstudent relationship based on interviews with the principal actors. We agree with Charlotte Herfray, [11] that the world of school, among others, is the place where the symptoms of our time are expressed, sometimes violently. Knowing this, one of our main objectives was then to understand how school context and personal relationships with teachers could play a role in students' relation to school on one side, and to knowledge, as defined by psychoanalysis, on the other side. We have discovered, as we will see below, that both school context and teachers play important roles in students' school experience, as well as in their wish to pursue their academic career. However, this comes with a price, especially for teachers, which is a new uncovered after a deeper investigation of teachers' discourses.

\section{Current social and school context}

Dropping out of school has an individual and an institutional constituent. It is an interplay of dispositions of behaviour of a student and his environment [12]. School dropout should rather be understood as a long-lasting process of disintegration, for which schools as an institution must take partial responsibility [13]. Findings show that the dropouts are a heterogeneous group. However, students with tendency to drop out of school often say they have trouble with teachers, face boredom in lessons, and/or they have a general aversion to school [14]. Many researchers identify links between repeating school years, bad grades in school, school absenteeism and eventual dropout [14]; [13].

The Luxembourgish Report on School Dropout [15] shows that $13,5 \%$ of pupils left school without their certificate in the 2014/2015 school year, which represents 1007 students, $0,5 \%$ more than the year before and 1,9\% more than the 2012/2013 school year. The main reasons, according to the report, are school failure $(22,1 \%)$, no access to desired training $(25,2 \%)$, inappropriate choice of training $(9,7)$, family reasons $(5,4)$ etc. $57,6 \%$ of school dropouts 
decided to quit school by themselves, and $22,3 \%$ said they didn't have any other choice but to quit school. "I also have problems both at school and outside school, which did not facilitate my academic career and after a while, I was completely unhappy. We can't follow the lessons and as time goes on, we will start stacking up until a certain moment we will stop the courses.".

The consequences of dropping out of school affect, without a doubt, both young people individually and the community as a whole; additionally, it has economics consequences. Often perceived as a personal failure by adolescents themselves, yet mostly by the society as claimed in the report "it is synonymous with inability to fulfil the basic social demands." [15]. However, it is important to keep in mind that the failing pupil can be, and mostly is, neglected by their teachers, their parents, and peers, as well as by themselves. However, they may be the one who neglects and drops off teachers, parents and peers. The report does not explain what is meant by "basic social demands", we can only assume that their meaning concerns the economic consequences, namely fitting into the labour market. They compare, if not equate, school dropout with an inability to fulfil basic social demands. This report is one of multiple examples in the current scholarly context. "If someone fails in the education system, he is rejected.". Is school still about learning, or has it become more about passing final exams?

The narcissistic society puts the individual at the centre of the world in a feeling of omnipotence; the quest for excellence and the cult of performance drive him into a quest for self-realization in which he maintains the illusion of being his own creator. Institutions are no exception of that layout [16]. Nowadays, schools are being asked to deliver students' performance based on international education policies, aiming thereby top places in national and international rank lists. Our hypermodern society, focused on measurement and educational outcome [17], constantly creates new recommendations; guidelines and pedagogical paradigms change depending on the ideological and economic context [3]. "Educational policies across Europe have focused on improving the quality of education, in particular through increasing the capacity for innovative teaching and reinforcing the professionalization of teachers." [3].

Therefrom, new frameworks arise in the scholarly system to "heal" the increasing school failure, school dropout, etc. The shift in the paradigm of competence requirements and the representation of knowledge on the Internet, in databases where access is sufficient, is conducive to the transformation of education into commodification. The technical mastery invalidates the experience and the knowhow of adults and elders, and the lure of "dialogue with the machine", relayed by the school and the media, imposes to new generations the unavoidable models of modern existence based on avoidance of the "transmissive" bond. However, in order to escape from the identifying link, according to the social paradigm of widespread 'instrumentalisation' and commoditization, adolescents (the privileged targets of advertising and family prescribers) are deprived of benchmarks that can support their adult development as subjects of their desire, and therefrom alienate themselves from the technologies that are supposed to free them [7].

Undeniably, the global educational ambiguity, related to constant innovations in the field, causes teachers to feel torn between tradition and innovation [18], consequence of these policies which places new demands on teachers by increasing their responsibilities, widening their duties and, more generally, changing their working conditions and status [3]. Teaching has become a joint activity, as teachers are encouraged to build partnerships with other professionals, parents, associations, etc., which makes the profession more publicly questionable [19]. Therefore, the school is inclined to tolerate very few deviations from both teachers and pupils. "It is well known that they (teachers) know that if the student continues like that, they will send him away and this is it, he is no longer a problem for them.". Consequently, the demand for help in schools does not come from the student himself (although he is the one suffering), but from the disturbance caused to the parents and the school.

However, the essential mission of schools, goes far beyond the transmission of knowledge. "By the end, is it important that they know how to solve an equation or is it more important to have social skills than knowledge?". To pursue a formal education is to prepare for the exercise of citizenship, to live together, to work, and to aim for equality. The school is a social link-building ground, where students and teachers request their place of Subject to be recognized. "Everyone has his way of being, you have to approach everyone differently,". The phenomenon of school disengagement as a symptom develops at the interface between the subject and the social, and therefore the subject traversed by the discourses of the Other. Some young people respond, because of lack of any other choice, through the symptom of "cutting themselves off" after a multitude of delusions on the part of adults. These same supposedly referential figures, are believed to be able to accompany them into the processes of subjectivation of their relationship to knowledge, and to take responsibility for it. "There are actually two 
factors that make them to dropout and to end at this school: the classic high school system did not suit them. And secondly, I would say, there is also everything, everything, everything, their history, their ... what made them unable to follow the school system. ". The act of leaving school could be the dropouts' way of assuring themselves that they are a Subject.

\section{SDropSy Research Project}

The research project "School dropouts as symptom of a subjective relation to knowledge $(s)$ " is a three-year intern project of the University of Luxembourg, which addresses the issue of school failure and early school leaving. The study is founded on a biographical and psychoanalytical approach based on the existence of the unconscious. Human communication, from a psychoanalytic perspective, is not a simple exchange between two individuals, but a discourse in which the subject speaks to another whom he creates by himself, even if that other can be incarnated in a fellow being. Our approach principally refers to Lacan's theory of the divided subject, defining the unconscious as being structured as a language by the signifier chains, with one signifier always referring to another. The signifier chain is built by signifiers connected to other signifiers by different ways, "links by which a necklace firmly hooks onto link of another necklace made of links" [20]. The associative links appearing in the discourses allow us to have a kind of understanding of the subject's unconscious desire, as there are in the unconscious signifiers chains, which subsist as such, and which, as they are structured as language, influence what appears from the outside as a symptom.

\subsection{Hypothesis and main aims}

Our conception of dropping out of school tends to consider it as a singular and collective symptom, induced by unconscious dynamics inscribed in the conflicting network of social, family, parental and institutional links, sometimes necessary for the emergence of the subject and the discovery of one's own desire. We believe that the act of dropping out of school is an act of the subject, an attempt at symbolization, which is often revealed as a symptom of a lack of subjective recognition on the part of parents and the school.

Our primary goal is to identify and understand the unconscious dynamics that can lead a student to leave school prematurely. The conditions of possibility for a change in the relation to knowledge of affected adolescents and young adults, as well as of teachers, is another one of our research aspects. Undeniably, we cannot discuss about teachers and students without including the school as an institutional discourse that has a significant impact on teachers; namely an impact on how they approach and build their professional identity and student relationships. We will be focussing on the relationship between teacher and student, and the impact that its quality could have on the student's desire for knowledge and student's motivation to pursue school, as well as its impact on teachers as both practitioners and subjects.

\subsection{Methodology}

We chose to organize our study on two aspects: by conducting interviews with teachers and students in two different high schools: a high school for young adults and a classic high school. We set up a schedule of three interviews with each participant, the first two being one year apart, and the last one 6 months later.

Each narrative interview lasted one hour and consisted of asking a general question (e.g. school career, changes during the year), then leaving the participant free to associate and develop certain points at their convenience. The researcher intervened to expand on certain questions and/or to support the participant in the deployment of their discourse, the latter is to ensure the discourse is as spontaneous as possible. The researcher has a psychoanalytical training and is thereby receptive to participants' speech and has the skills to deepen some questions without causing any harm to the participant. The spontaneous discourses by association allow us, after analysis, to identify unconscious links and conflicts, as well as the desire for knowledge and lack of desire for knowledge; family configuration and its link with personal trajectory, as well as possible tension between institutional and personal discourse. The discourse referencing the unconscious is thus a repository which makes it possible to re-read the events, considering more of a logic of meaning and significance than of causality.

We are very strict with our researcher's ethics, as such we were very careful during each interview, our goal was not to create an unpleasant experience for the participants. All the participants were told the same framework points as follows: interviews are anonymous and confidential. We asked them for authorisation to record the interview. We had one participant who refused, which we did accept. We also lost several subjects as the time of the study went on, as some simply did not respond to our next solicitation. Some said they did not want to pursue the interviews; others approached us to explain their wish to end participation. It is, as it is called, the vagaries of research on the field.

That said, we managed to complete all three interviews with a total of seven teachers and five 
students. We decided to include also the twointerviews participants. The multiple interviews process shows various aspects of the relation to knowledge of every participant, as well as the possibility for us to identify a potential development in the discourses on various topics. Mostly, we have the dynamic of narrative construction and deconstruction of identity and of the subject's position.

\subsection{Interviews}

In this paper, we will be focussing on the interviews of teachers and students from the high school for young adults. We will present our discovery-based thoughts and questions based on what we discover after analysing these interviews. Our methodology brings a two-fold point of view to the institutional framework. On one side, we acknowledge the institutional discourse appearing through interviewee teachers and their opinion on their mission within the school. Based on psychoanalytic analysis of their discourse, we could identify, beyond the way they approach the institutional policies, how they manage to build a bond with students via tutoring; we also identified effects on their professional and personal experiences of the outside the classroom relationship to the student. On the other, we collect students' personal impressions of both the institution and the teachers as executives of the institutional strategies. Likewise, these young people are familiar with the classic school system, which most of them have left; consequently, they have further reflections on the positive and negative aspects of school. The analysis of their discourses shows the primacy of subjectivity in how they consider school and teachers, governed by their own previous experiences.

First, we will explain the institutional particularities of this school for young adults. Then, we will discuss the importance of the teacher-student relationship and its impact on students' desire for knowledge by using students' and teachers' interview quotations. We will conclude by touching on teachers' occasional difficulties with understanding and applying institutional demands; additionally, we will discuss the effect that a more personal relationship with students could have on teachers, notably the tension between unconscious knowledge and academic knowledge, as contained by an institution, which leads teachers to concede and compromise.

\section{High School for young adults}

The high school for young adults is a relatively young establishment which opened in 2011. The institutional policy is based on a close relationship with students and the scholarly program is adapted to students' life. "The pupils are much more the centre than in the classical high school. I get the impression, given that we have this tutoring system, here, we take care of the students individually.". As the students are adults who often work and have families, the school proposes adapted trainings to everyone. "Since these students here they've strayed because the so-called classical system no longer suited them at all, so we must certainly have recourse to other means, which are precisely that of the tutoring and of the care of the pupils. They are more supported than, I would say, in classical high schools.". The small number of students per class (10 to 15) is one of the consequences of school policy. "It makes a huge psychological difference"

\subsection{Body of teachers}

Each teachers' team oversees two to three classes of learners. Teachers are responsible for the reception and recruitment of learners, which is made by a level test determining each student's class. "The position is not the same for the teacher than in the classical high school, but ah, we must nevertheless also know that we are, above, all teacher and uh we must never take the position of a psychologist or 'a doctor'.,

The teachers' team organizes the training, monitors learners' progress, and defines the didactic methods and the improvement measures to be proposed. Teachers collaborate in a weekly or biweekly meeting. "We have meetings every week, we talk about students, they know it. It can bother them, but too bad for them, they can go to another school where no one cares."

\subsection{Tutoring}

The pedagogical team chooses from among its members, for each learner, a tutor responsible for the organization of tutoring. The weekly tutoring, comprised of 30 minutes one-to-one time between teacher and student, is mandatory. "They always go to the tutoring, they will always tell you what happened at home, not always but often, and uh I always take some distance because it's not my role, I'm not their parents, I'm not their psychologist, I'm not their doctor either, I tell them yes it's your privacy, I can understand but um ... ". The main aims, according to the few documentations we found about the tutoring's framework, are to help students: improve their learning skills, find additional help/solutions to students' personal/scholarly difficulties, and to define a professional project for students. According to teachers, "The tutoring actually aims to control how they learn, to see if they work well, if they have problems in a field, to organize remedial classes. But, uh, from time to time, there is still privacy that comes up, and we're not 
safe.". For some other teachers, this one-to-one time is about understanding students' difficulties.

\subsection{Overview of teachers' and students' discourses}

It is interesting to note that some topics, issues or positives aspects of the institution and everyday life with each other are clearly mentioned in all the teachers' and students' discourses.

4.3.1. Teachers' discourses. Teachers' discourses reveal that the reduced number of students in class is a pleasant aspect of their work. Indeed, students and teachers agree that fewer students in class is beneficial for both of the parties because it allows teachers to be more aware of some students' difficulties, and to spend more time with those pupils. "I feel that the organization is more chaotic here than in a normal school because there are so many different situations of the learners that you have to manage a lot more than in a school or another school." As it is a young high school that is still developing and improving, sometimes teachers feel overwhelmed by the institutional work and administrative tasks they are asked to accomplish.

For teachers working with young adults rather than with pupils/adolescents, their work is described as very pleasant despite the occasional lack of maturity in some students. "I have never felt this kind of stuff in this sense where the students here are, what I said before, they are between teenagers and adults but they are often teenagers."; "I find that their maturity is not so great here, it is in any case, it is not what I expected before I've come. So, the problems that they had when they were 15 years old, they carry them with them until their 20 years".

Regarding the adapted training, some students are often absent, which make catching up with studies difficult. All interviewed teachers agree that most of their students lack studious methodology and a rigorous work ethic, making it harder for both students and teachers to learn and transmit knowledge. "This organization, this discipline, I have the impression that they have never learned and that when they are 18-20 years old, it is very difficult to start what has never been done. And tutoring is too short to really work on methods how I learn, how I study."

Working in a pedagogical team is highlighted and highly appreciated for teachers. "It's the team that is the strength of our team.". It is an exceptional place of speech where all problems of a student are addressed within these team meetings.

4.3.2. Students' discourses. Students' discourses reveal that the professors are more demotivated in the classic school than in this high school for young adult where teachers are much more involved in students' academic and personal lives. "We know them, they know us. We go well together and then they know well, as I said before, we respect them, they respect us here ... too. So, we talk .... it's something other than the level of a normal high school, it's not that ... this way is a little above the things and so, well, that's good. ". "The vast majority of teachers are really good. They are cool, they are relaxed, they already accept us as adults, it is not the way as a nursery school to have classes, because we also respect them obviously"

Students still find the courses uninteresting and sometimes inapplicable to the real life; here, the question "What's the point" stays in their mind.

4.3.3. Common point. The ultimate goal for both teachers and students is pupils passing their finals and thereby having the certificate for "a better life". "They absolutely want us to pass, which is good. It would be sad if they did not care too much, it would be serious too."; "I think they want us to succeed".

\section{Knowledge as a common object between teacher and student}

A knowledge can be considered both as an external object to the subject, existing socially, as a part of the self, on which the subject is structured, or as the attribute of an 'other' who will or will not accept that this knowledge will be taken by someone else. The knowledge always comes from an 'Other', real or fantasized [7]. Consequently, we consider the knowledge to be a psychic object, the relation to which is strongly influenced by both institutional bodies and personal long-lasting life experiences, which include unconscious conflicts. Thereby, we identify two relations: the personal/unconscious relation to the object of knowledge; and the relation to the institution providing the knowledge. Every institution has two sides: a slope that refers to organizational and objective facts, and a slope that refers to subjective psychic facts in which desire is involved. The reaction of members of the institution is a question of transference [11].

The school is a third space between the student and one's family. Each student experiences the school differently and feels different emotions. The family discourses, the images, the speeches of the television are not without effect on the experience of the student. Going to school represents a meeting with specific social rules, which can break up with the family's habits. The teacher is representative of these social rules, which they are inclined to transmit following institutional requests. The concept of 'transmission' into school can aim at respecting the rhetoric of knowledge, as it can be done in order to enable the pupil's acquiring and personalization of knowledge. 
Knowledge constitutes an easy mediation to place the subject. Through the "relation to knowledge" subjects are inscribed into the symbolic dimension, and so they are divided by the signifier, which also conditions them as beings of desire. Thereby, the relation to knowledge is an emotional bond; understood as such, it is a matter of involving the students in their learning by acknowledging their questions as worthwhile, and by leading them to understand their own complexity. Teachers, unconsciously, represent modes of incarnation of knowledge through which learning takes place, each teacher embodying a mode of transmission of knowledge, per his very motivations, his personality, the way in which he apprehends the profession and the class. The teacher can be a figure that transforms the student whose subjective relation to school and knowledge is marked by the specific relationship, good or bad, with the teacher. The school experience of students is impacted by the relational skills of the teachers as well as from their didactic skills.

Knowledge as an object, in the psychoanalytic sense of the term, represents a support for the emotional and unconscious investment, submitted as such to projections and fantasies. In other words, the choices and interests in one field and not in another are influenced by our unconscious investment and experience. One participant, a student who had dropped out of school and has since joined this school, said that literature is one of his nightmares. He explained that reflections on emotions, especially love in novels, unnerved him; he spoke as if all affect and allusion should be kept away. Mathematics, computer science and economics are the subjects that interest him and which, because of their concrete content devoid of any sentimentality, are sufficiently safe enough for him to enjoy. He "prefers to work with numbers rather than words.". This love for numbers and hate for words could be explain by his relationship with his father (and his rational, scientific way of thinking) and the one he entertains with his mother (feminine and emotional). Thereby, knowledge involves relation to a symbolic boundary; it is something of the order of a space in which the subject can find his voice within his discourse. Desire plays an essential role here.

Within psychoanalysis, the concept of "desire" does not suggest a goal to reach or a full satisfaction to find. It is about reproducing itself as desire. The term "desire", which has quiet means, has thus become a specific concept of the Freudian theory, showing that our behaviour is not programmed by our biological heritage; rather, it is related to how we live with our lacks and in what manner we have been able to work them, given the wealth or symbolic poverty we have inhabited and the words of those who chose to raise us [11]. Hereby, it is not about the target; it is about the motion driven by the objectcause of desire. This object is not what we desire or what we pursue, it is what sets our desire in motion, a structure that confers consistency on our desire, regarding social bonds and interdictions. In here, every individual originates their own fantasy. The knowledge of drive assumes a form of knowledge of the subject's fundamental fantasy which regulates the admittance to 'Jouissance'.

The relation to knowledge would be the passageway from an interest which does not know itself to an interest that knows itself [6]. The active presence of the teacher is a necessity so that he consents to take this step, aside or forward, to get the pupil out of his blind alley. This could not happen without his desire to be involved beyond the minimum requirements of his teaching practice. "There are always two types of teachers. There are those who come to school to do their work and there are those who really commit themselves." It is a complex act involving challenging the law of simple pedagogy (I must transmit this knowledge) by the law of desire, the law of the subjective aspect. "If the teacher is involved as a teacher and wants to do well his course and everything ... and after there is no ... class response or even ... that also discourage them". We could say it is a crossing point between the desirable dimension of the teacher and the subjective dimension of the student as a subject. "They accept us as adults. Because we respect them too."

The theory of "desire" escapes the criteria of evaluation of theories based on observation and measurement. Psychoanalysis is a heuristic (it is not a constituted knowledge, but a research always in movement) coming from the conjectural sciences. The latter considers phenomena which are not visible but do not cease to have an effect [11]. This desire, seen as a little 'bypass', challenges the teaching discourse, especially because it is not included in the year's official program, nor in the initial training. "I have the impression that there are a lot of teachers here who are here not because someone put them here, but because they wanted to be here. That already changes a lot.". The subject is structured through identifications with subjects representing its ideals. Freud identifications are unconscious psychic acts. The psychic rearrangements are often rearrangements in the ideals. They are often possible through positive transference links with highly invested "respondents" who will be important allies for the subject [11]. The sympathy and the confidence operate as positive supports of the pedagogical and educational relation. These affects constitute a kind of second chance for damaged subjects.

Thereby, the most important aspect is not the transmission of knowledge but the transmission of the desire for knowledge. The set of signifiers constitutes the nucleus of knowledge and discourse, which represents all that can be put into meaning and 
exchanged with the other side of the relation [6]. Knowledge is therefore the set of accumulated past experiences, linked together. The relation to knowledge is thus not a fatality, something fixed, which once built can no longer change, there are possible transformations of the relation to knowledge as much in the young as in the teachers.

\section{Teacher-student/Student-teacher}

The teacher-student relationship must remain within a symbolic space framed by the transmission of knowledge as a common object, bounded on one side by the one who wishes to transmit knowledge, and on the other by the one who wishes to learn it. The relationship established between student and teacher has a significant impact on how students approach school, and particularly knowledge. "I like that the teachers of languages tell me that I have quite high capacities in writing and all that." Students are more likely to pursue their schooling when they feel comfortable and supported by their teachers, due to the singular bond encouraged by the institutional framework. "We pay greater attention, from the very beginning of the course, if we know that it is a teacher whom we like and his course is interesting." Therefore, we can say that interviewee teachers establish a personalized relationship with students, thus demonstrating a systematic adjustment of their professional position throughout their career.

Their commitment to the students' academic success is therefore strong, due in part to tutoring and the small number of students per classroom. "Our first goal is to make them pass the year, even if we must take them by the hand; afterwards, he has to manage on his own.". Students should feel this availability of teachers who have an interest in the students' active or passive behaviours. "During class time, I try to limit myself to the course topic, and if there is need to discuss something else, will be during the break or it will be on another time." The teacher is the driving force in the construction of a shared psychic space in which the desires and needs of each other circulate by tolerating risks and uncertainties. This allows a distance from the risk of an identification with the idealist and idealistic professional role. "Personally, I think we should play fair game, say things the way they are and not announce something we will never do.". Each teacher has their traits, values and principles that are transmitted, voluntarily or unknowingly during their relationship with the student. "Teachers do not always have reasons, students are not always right, I think we have to hold together and try to sustain each other."

We would say that the personal, more present and involved relation that teachers tend to have with students, is a positive way to encourage students and to help them stay on track with their academic career. "We will nevertheless transmit to this youth our way of doing, our optimism, our vision, and we leave traces in the lives of these young people. That's clear".

This is a two-way approach: on the one hand, teachers receive feedback from their students and are more likely to call their practice into question. On the other, the students feel supported by both the teachers and the institution which authorizes the parties to get more involved; the question of a third party is present. This type of institutional framework favours the relationship between teacher and pupil, on the condition that the institution supports and encourages it. However, in the context of liberal globalization, whatever the level or specificity of their pedagogical practice, teachers are now carried away in and through the policies, as we said in the begging, that destabilize the representations and investments that support their conception of the profession; and question their symbolic place in social hierarchies. The teaching condition as a whole is nowadays being called into question, and it is at work that difficulties and individual suffering are mostly ignored. The destruction of founding values, the destabilization of symbolic benchmarks and containers, the transformation of aims, modalities, content and evaluation of practices, attack the foundations of professional identity in which it is now difficult to recognize itself as the subject of his action.

As our project neared its end and we delved deeper and deeper into analyses and thoughts, we found out that, despite these previous positive findings, teachers suffer. This is due to lack of training and a lack of necessary documentation from the institution; these issues are explained below.

\section{The dark side: unconscious aspects}

The difference between the subject's manifest discourse and the subject's personal unconscious discourse, which reveals itself being disguised by/from the manifesto, is particularly interesting for further analysis. As a result, being unable to make the institutional discourse one's own, while at the same time believing in it as one's own, becomes a source of suffering for the interviewed participants who want to do well but who do not know how due to divergence between what is expected from them and their subjective unconscious desires. This is as true as this particular school is centred on an individual relation with student via tutoring, and that is a transference ground.

Tutoring consists of in each student having his/her own "personal coach" who accompanies him/her throughout his/her training, as we explained above. "The tutor is a mediator between the student and the team which meets once a week and where each student is discussed". This set-up provides for a 
more individual, and thereby personal, relation between teacher and student. "Tutoring is a matter of availability so that students have a reference person. For me it is not a matter of 'seizure'."

Tutoring combines the cognitive and social dimensions of learning in the same dynamic, based on a logic other than the one developed in the school environment, which is no longer a matter of pedagogy, but of interaction. The engagement in this set-up produces great ambivalences among teachers. "I have always had problems of distance and near heart.". The latter, for many, had many years of experience in classical education before joining this school, where tutoring does not exist. They find themselves obliged to be part of this system without, however, the institution specifying their role, their function, their status. "The difficulty comes from knowing where the boundaries are, it's not always obvious and uh, I have to tell, me personally, it bothers me.". Engaging a work-in progress on their personal involvement in the student relationship does not present any evidence for either the institution or the teachers. "Well we are, we are not psychologists, no I, I am not a professional psychologist, I would never dare to say that. But we are nevertheless, we must still have a certain, ah some approach...".

The teacher cannot control how it will be perceived since each student perceives it in his own way. Thereby, each student could feel comfortable with one teacher and not so comfortable with another. Students can enjoy different matters just because of the presence of the teacher. The teacher would be the support allowing the emergence of students' interests and motivations. "I want them to learn, so I will always try to take the step to make something happen". His/her mission is to guide the student towards defining himself as a person, accepting himself and progressing. "My favourite teachers, you could see that they like their job. It really encourages you to want to go into their class." In other words, the school has the role of contributing to the development of everyone, as well as of teaching a common knowledge that will enable students to participate in the social community. "You have to take them seriously for sure. And they have things to say." So, the institution is the one who defines the place to every actor in it. Although, "we do not have an exchange that is purely academic, it does not exist.". When the institution is not clear about the framework, that leads to personal suffering.

One of the participants explained a few situations to us that were sources of suffering for her as a person more than as a teacher. She heard that students said she did not listen to them. Being able to listen to students is a trend in our hypermodern society; therefore, this accusation was an insult for this teacher. "They shouldn't say it because I'm always there for my pupils, well I believe it anyway, I think.". After a deep analysis of her three interviews, we could say that this woman has personal issues of insecurities due to her personal, long-lasting life experience. Being a teacher in this school is something of great importance to her, and there she finds herself surrounded by meaning and respect, which was not the case in her former work environment. "It's a matter of the feelings you really need to know how to cut out at some point". The impression of not receiving a positive feedback and the narcissistic wound produced by the students' saying of rejection, conveys this teacher to originate her suffering and her discouragement, corresponding with her commitment to the educational task. This is not merely the demand for love which obscurely sustains and energizes the pedagogical link, but rather the feeling that the professional narcissistic contract has not been respected by the students, that efforts are ineffective in carrying out the primary task and that there is no recognition. When she hears students criticizing her professional skills and attitude, she is not able to distinguish the line between personal and professional identity. "That made me sorry outright ... it still hurt me. Their blames really hurt me. The fact of dropping it on me was uh it was hurtful; it was really hurtful". Their academic suffering takes place on the unconscious stage, where the relation between the Subject and the Knowledge is played out, where the real and the imaginary biography of the individual, their journey, their continuities and ruptures, are mixed. "It's still not always easy to ... endure all this".

Undeniably, tutoring affects teachers. They do not choose their students, so sometimes they are tutors and teachers for the same students: "we are both tutor and teacher, where we give notes and this causes even problems", which is a double role not so easy to hold. "If the person doesn't say anything, I talk about myself. If one stays impersonal, it does not give anything. We have more or less affinities ... you have to know 'how to',". These affinities built during the school year, especially between tutor and tutee are not without effects on teachers. "I have really tried everything. I even did therapy with him. But he did nothing. And that hurt me a little. He said, 'the teachers are against me and that's why I will not succeed'. But we really did everything.". Student's failure could become personal/professional failure for the teacher, even if "despite everything I did, I did not succeed ... well, it's not my responsibility either, but ... we did not succeed, all the teachers, we did not succeed.". As we can see here, this teacher struggles between her own, and personal, involvement in the student's schooling, and the fact that she shouldn't be alone, she is a part of a team, of an institution. How to have clear position on it since the institution has not be clear on it?

As we said, teachers work in teams and are constantly exchanging information. "We work very, very, very well together. We are a team and we 
support each other all the time.". Some of the teachers became defensive when asked in more details about their relations within the team in question. But some of them said what they were feeling "I work a lot with the manager. It also creates jealousies.". Sometimes there are situations where personal fantasies pop up after hearing what other teachers say. "When, during a team meeting, I had heard that, he (student) said unappropriated things behind the teacher's back, I could imagine that it was in my course. (...) I told my-self I have to listen more carefully, to try to understand what he says.".

The school seems to be very flexible and teachers have the liberty to build their course organisation as they want. "And I would say that in classical high school there are still many teachers who still try to talk to the students but it is true that the framework does not always allow". It seems to be freer than in a classic school, where everything should be where it should be. "I was someone who tried to take care of the students, but the large staff ... I did my job, I did my class but I could not follow the students. And that always cost me. ". But once we started to question it, it seems that there is a lot of mandatory time where teachers, as well as students, are bound by some rules not explicitly defined; consequently, each teacher seems to take them as he/she can or want. "We are a team, we see each other every week, so let's say we are even forced to work with the others in the team."

The question of how the institution takes care of the students is the core of the institutional framework. The accent is placed on personal and social aspects in order to identify the main issues (i.e. possible reasons for dropping out of school), and thus to help the students get through the school and to pass their finals successfully. As we said in the beginning of this paper, schools are looking for performances and high numbers. This young school is no exception. But, we also said that school is for preparing young people to live after school, to live together, to personify social rules. "Yes, yes, the school prepares for the after school, each tutor must speak with the student and knows what he wants to do after the finals.". Although, "here, they are pampered, spoiled too. We have full measure, we have tutoring, everyone is there for the students. But, when you're alone in college you do not have that anymore, you're alone, and if you're going to work, get by. ". As we mentioned here above, nowadays we have real-time access to all knowledge, but the rise of insignificance seems inevitable. Individuals no longer know what sense to devote themselves to [16]. This loss of meaning experienced by many of students, is the expression of a world lived as incoherent and paradoxical. Is it one of school's mission to guide young people into this significance research by transmitting them beyond the simple knowledge necessary to pass the finals? "My personality I did it at the university and not at school. I think that at school there is no place to forge a personality.". It would be interesting to interview these same students a couple of years after they pass the finals to see how they deal with the "after math". A topic for a new research.

\section{Conclusion}

Beyond the conscious goal (passing the finals), teachers support students' developing desire for knowledge by being present and dedicating their time (via tutoring), particularly within an institutional framework that encourages the bond between teacher and student. Both interviewed teachers and students share positive experiences within this high school for young adults. Teachers themselves feel supported and encouraged by the principal and the vice-principal, the latter plays a significant role in teachers' and students' life as he participates to all team meetings.

Tutoring has a significant impact, mostly on teachers. This institutional setting puts them into a role for which they are not prepared. Thereby, teachers are confronted with double discourse and double constraints (teacher and tutor) that lead them to survive, to invest defensive strategies, and sometimes, to deny their distress. Additional training and supervision/following up sessions with teachers seems, in our opinion based on the interviews, to be necessary.

The analysis leads us to the conclusion that the discourses, within which we live, are often in divergence with those that are kept hidden in the unconscious; the latter though, being well hidden, are at the same time responsible for building subject.

\section{Acknowledgements}

We are grateful to the institution, namely the principal and the vice principal, to be so kind to open their doors to us; it was a rich collaboration. We are also very thankful to all participants who gave us some of their precious time, and played a fair game with us.

\section{References}

[1] Diet, E., (2005) "Enseignants en souffrance", Revue internationale de psychosociologie, (24), pp. 97-117.

[2] Blaise, M.-C., Gaucher, M., and Ottavi, D., (2008) Condition de l'éducation., Stock, Paris.

[3] Eurydice European Unit, (2008), Levels of Autonomy and Responsabilities of Teachers in Europe. Eurydice, Bruxelles,http://eacea.ec.europa.eu/education/eurydice/doc uments/thematic_reports/094en.pdf 
[4] Freud, S., (1933), "Conférence XXXIV, Eclaircissements, applications, orientations", in Nouvelles conférences d'introduction à la psychanalyse, FolioEssais, Paris, 2000, pp. 182-210

[5] Lacadé, P. (2013). La vraie vie à l'écle. Editions Michèles.

[6] Lacan, J. (1975). Le Séminaire Livre XX (1972-1973). Paris: Le Seuil.

[7] Hatchuel, F. (2005). "Rituels d'enseignement et d'apprentissage". La Revue, 43, (3), Hermès, pp. 93-100.

[8] Petiot, O., Visioli, J., and Desbiens, J.-F. (2015, 4). "Perceptions d'enseignants du secondaire concernant leurs inducteurs émotionnels en situation de classe". Revue française de pédagogie (193), pp. 41-56.

[9] Baker, J. A. (2006). "Contributions of teacher-child relationships to positive school adjustment during elementary school”. Journal of School Psychology, (44), pp. 211-229

[10] Muller, C., Katz, S. R., \& Dance, L. J. (1999, 3). "Investing in teaching and learning dynamics of teacherstudent relationship from each actor's perspective". Urban Education, (34), pp. 292-337.

[11] Herfrey, Charlotte (2006). La psychanalyse hors les murs, coll. Psychanalyse et civilisations, L'Harmattan, Paris

[12] Ricking, H., (2006), Wenn Schüler dem Unterricht fernbleiben. Schulabsentismus als pädagogische Herausforderung., Bad Heilbrunn, Klinkhardt Verlag

[13] Stamm, M. (2015). Schulabbrecher oder: Wer bricht denn hier was ab?, http://margritstamm.ch (11.3.2015)

[14] Hillenbrand, C., \& Ricking, H. (2011, 2). "Schulabbruch: Ursachen - Entwicklung - Prävention. Ergebnisse US-amerikanischer und deutscher Forschungen.". Pedagogik (57), pp. 153-172

[15]http://www.statistiques.public.lu/fr/publications/thema tique/conditions-sociales/decrochagescolaire/decrochage.pdf

[16] de Gaulejac, V. (2011). "L'injonction d'être sujet dans la société hypermoderne : la psychanalyse et l'idéologie de la réalisation de soi-même". Revue française de psychanalyse, (75/4), pp. 995-1006.

[17] Biesta, G. (2009). "Educational Assessment, Evaluation and Accountability". Journal of Personnel Evaluaiton in Education, 21(1), pp.33

[18] Pechberty, B. (2003, 3). "Apports actuels de la psychanalyse à l'éducation et l'enseignement : un éclairage fécond". Ela. Etudes de linguistique appliquée(131), pp. 265-273.
[19] Chartier, M., \& Payet, J.-P. (2014, 2). "Comment ça se passe à la maison? Troubles du rôle professionnel dans l'entretien enseignant-parent". Revue française de pédagogie, (187), pp. 23-34.

[20] Lacan, J. (1966). Les écrits. Le Seuil, Paris, 2000 